\title{
Effect of Beta-Blocker Cardioselectivity on Vascular Refilling in Hemodialysis Patients
}

\author{
Marta Álvarez Nadala Elizabeth Romelia Viera Ramírez ${ }^{a} \quad$ María García Vallejo $^{a}$ \\ Irene Martín Capón ${ }^{a}$ Milagros Fernández Lucas ${ }^{a}$ b \\ aDepartment of Nephrology, Hospital Universitario Ramón y Cajal, IRYCIS, Madrid, Spain; bUniversidad de Alcalá, \\ Madrid, Spain
}

\section{Keywords}

Hemodialysis · $\beta$-Blocker - Carvedilol · Vascular refilling .

Absolute blood volume $\cdot$ Intradialytic morbid events

\begin{abstract}
Background: $\beta$-Blockers are the most frequently prescribed cardioprotective drugs in hemodialysis (HD) patients, despite their weak evidence. We sought to evaluate the effects of $\beta$-blockers on vascular refilling during HD treatments and examine whether carvedilol, for being noncardioselective and poorly dialyzable, associates more impact than others. Methods: The study was performed in a cohort of maintenance HD patients from a tertiary center. All patients had previous $\beta$-blocker prescription. We conducted a prospective crossover study and measured vascular refilling volume $\left(V_{\text {ref }}\right)$ and vascular refilling fraction $\left(F_{\text {ref }}\right)$ in 2 circumstances: under $\beta$-blocker treatment ( $\beta$ b profile) and without $\beta$-blocker effect (non- $\beta b$ profile). Results: Twenty patients were included, 10 of whom were treated with carvedilol. Predialysis values were comparable between the 2 profiles. Although the $\beta b$ profile showed lower $V_{\text {ref }}$ and higher ABV drop, these differences did not reach statistical significance. Data showed an increase in $F_{\text {ref }}$ in the non- $\beta$ b profile $(70.01 \pm$ $6.80 \%$ vs. $63.14 \pm 11.65 \% ; p=0.015)$. The $\beta b$ profile associ-
\end{abstract}

karger@karger.com www.karger.com/crm

Karger $\stackrel{\text { ' }}{5}$
C 2021 The Author(s).

Published by S. Karger AG, Basel

This is an Open Access article licensed under the Creative Commons Attribution-NonCommercial-4.0 International License (CC BY-NC) (http://www.karger.com/Services/OpenAccessLicense), applicable to the online version of the article only. Usage and distribution for commercial purposes requires written permission. ated a significantly higher risk of intradialytic hypotension (IDH) (risk ratio $2.40 ; 95 \% \mathrm{Cl}: 1.04-5.55)$. When analyzing separately the carvedilol group, patients dialyzed under drug effect experienced a significant impairment in $V_{\text {ref, }} F_{\text {ref, }}$ and refilling rate. Conclusions: Administering $\beta$-blockers before $\mathrm{HD}$ associated a higher risk of IDH and a decrease in $F_{\text {ref. }} \mathrm{Pa}$ tients dialyzed under carvedilol effect showed an impaired refilling, probably related to its noncardioselectivity and lower dializability.

(c) 2021 The Author(s)

Published by S. Karger AG, Basel

\section{Introduction}

Cardiovascular $(\mathrm{CV})$ disease is a major cause of morbidity and mortality among hemodialysis (HD) patients, with a prevalence up to 3 times higher than that observed in other groups at risk [1]. There is wide evidence showing beneficial effect of cardioprotective medications, such as $\beta$-blockers, in decreasing CV morbidity and mortality in general population. However, most clinical trials that analyze $\beta$-blockers' cardioprotective effectiveness exclude dialysis patients due to the risk of side effects [2-5]. Despite the poor evidence, $\beta$-blockers remain the most common $\mathrm{CV}$ medications prescribed in HD patients, based on their 
Table 1. Pharmacokinetics of $\beta$-blockers included in the study (15-19)

\begin{tabular}{|c|c|c|c|c|c|}
\hline & Cardioselectivity & $\begin{array}{l}\text { Lipid } \\
\text { solubility }\end{array}$ & Elimination & $\begin{array}{l}\text { Half-life }\left(T_{1 / 2}\right) \text {, } \\
h\end{array}$ & $\begin{array}{l}\text { Maximum plasma } \\
\text { concentration }\left(\mathrm{T}_{\max }\right), \mathrm{h}\end{array}$ \\
\hline \multicolumn{6}{|l|}{$\begin{array}{l}\text { Moderate } \\
\text { dialyzability }\end{array}$} \\
\hline Atenolol & Yes & Low & Kidney & $6-8$ & $2-4$ \\
\hline Metoprolol & Yes & Moderate & Liver & $3-4$ & $1.5-2$ \\
\hline \multicolumn{6}{|l|}{ Low dialyzability } \\
\hline Bisoprolol & Yes & Low & Liver, kidney & $10-12$ & $2-4$ \\
\hline Carvedilol & No & Moderate & Liver & $6-8$ & $1.5-2$ \\
\hline
\end{tabular}

proven efficacy in patients with normal kidney function [6]. Their mechanisms of action include [7] blood pressure (BP) lowering (due to a decrease in cardiac output), anti-ischemic action (by reducing heart rate, cardiac contractility, and systolic blood pressure), antiarrhythmic activity, inhibition of renin release and angiotensin II production (which also contributes to BP control), and left ventricular ejection fraction improvement $[8,9]$.

Only 2 randomized controlled trials (RCTs) have explored $\beta$-blockers' benefits in HD patients [10]: one comparing carvedilol to placebo in HD patients with congestive heart failure and dilated cardiomyopathies, showing a reduction in morbidity and mortality in the carvedilol group [11, 12]; and a second study comparing atenolol to lisinopril therapy in HD patients with left ventricular hypertrophy and hypertension, which showed atenolol's superiority in preventing CV morbidity and all-cause hospitalizations [13]. A third RCT by Roberts et al. [14] comparing carvedilol to placebo attempted to compare all-cause mortality and CV event incidence; however, they were unable to recruit planned sample size. It should be taken into account that effectiveness may differ among agents, as intradialytic kinetic is likely to vary between $\beta$-blockers: while the literature shows that atenolol and metoprololare highly dialyzable, bisoprolol and carvedilol clearances remain lower [15]. It is also important to consider $\beta$-blocker selectivity: atenolol, metoprolol, and bisoprolol show cardioselectivity, while carvedilol is considered noncardioselective (Table 1) [16-20].

Intradialytic hypotension (IDH) is a frequent complication during HD treatments, occurring in up to $20 \%$ or more of dialysis sessions, and it associates significant morbidity secondary to end-organ hypoperfusion [21]. It is the clinical manifestation of a drop in absolute blood volume (ABV) due to ultrafiltration (UF) rate, not compensated by vascular refilling volume $\left(V_{\text {ref }}\right)$ from interstitial to intravascular compartment. The use of $\beta$-blockers may impair intradialytic physiologic compensatory responses to ABV drop and contribute to IDH development [22]. However, there is scarce evidence supporting this hypothesis, as ABV and $V_{\text {ref }}$ measurement has not been easily accessible to direct investigation for years [23]. Recently, a new methodology has been reported that allows clinicians to easily and noninvasively calculate $\mathrm{ABV}$ and estimate $V_{\text {ref }}$, based on the infusion of $240 \mathrm{~mL}$ of purified dialysate and the analysis of RBV changes [24,25]. A first retrospective study conducted by our group suggested that HD patients under $\beta$-blocker treatment tend to have lower vascular refilling fraction $\left(F_{\text {ref }}\right)$ [26]. It is the aim of this study to analyze how $\beta$-blockers modify vascular refilling during HD treatments and examine whether carvedilol, for being noncardioselective and poorly dialyzable, has more influence on intradialytichemodynamics than other $\beta$-blockers.

\section{Materials and Methods}

\section{Participants}

The study was performed in a cohort of maintenance HD patients from a tertiary center and was approved by the local ethics committee. Inclusion criteria were ages $>18$ years, previous $\beta$-blocker prescription, and ability to read informed consent. All subjects were dialyzed thrice a week under online hemodiafiltration modality and high-flux dialysis membranes.

\section{Study Design}

We conducted a prospective crossover study, using the blood volume biosensor (BVM) included in 5008 online hemodiafiltration monitors (FMC ${ }^{\circledR}$; Bad Homburg, Germany). Every patient had ABV, $V_{\text {ref }}$, and $F_{\text {ref }}$ measured in 2 different circumstances: un$\operatorname{der} \beta$-blocker treatment ( $\beta$ b profile) and without $\beta$-blocker effect (non- $\beta$ b profile). For the $\beta$ b profile, patients were asked to take the $\beta$-blocker $2 \mathrm{~h}$ before the dialysis treatment (according to average drug maximum plasma concentrations), and for the non- $\beta$ b profile, $\beta$-blockers were discontinued following each drug half-life 
(Table 1). Measures were performed in a randomized order, all of them in the first dialysis treatment of the week. Dialysate temperature was maintained constant at $36.0^{\circ} \mathrm{C}$. UF volume was established according to clinical criteria.

\section{$A B V, V_{\text {ref }}$ and $F_{\text {ref }}$ Measurement}

$\mathrm{ABV}$ at the beginning $\left(\mathrm{ABV}_{\mathrm{b}}\right)$ and at the end $\left(\mathrm{ABV}_{\mathrm{e}}\right)$ of the dialysis treatment, $V_{\text {ref }}$, and $F_{\text {ref }}$ were calculated using the methodology recently proposed by Kron et al. [24, 25]: RBV was continuously monitored by BVM. Treatments were started without UF. Within the first 15 min of the treatment, $\mathrm{ABV}_{\mathrm{b}}$ was calculated by infusing $240 \mathrm{~mL}$ of ultrapure dialysate into the venous blood line, at a rate of $200 \mathrm{~mL} / \mathrm{min}$. Blood flow was reduced to $50 \mathrm{~mL} / \mathrm{min}$ during bolus administration. RBV was recorded before and immediately after the procedure. Once the measure is completed, UF must be started, adding the volume infused for the test in order to achieve dry weight.

Initial ABV was calculated as

$$
\mathrm{ABV}_{\mathrm{b}}=\frac{V \text { bolus }}{10 \times(\text { Post RBV }- \text { Pre RBV })} \text {, }
$$

where $\mathrm{ABV}_{\mathrm{b}}$ is measured in liters (L), $V$ bolus is the volume of the bolus infused (measured in milliliters, $\mathrm{mL}$ ), and Pre-RBV and Post-RBV are the RBV measured immediately before and after the bolus infusion (measured in percentage, \%).

For calculating $\mathrm{ABV}_{\mathrm{e}}$, there is no need to infuse another bolus, and only RBV must be recorded in the last 15 min (Final RBV). The $\mathrm{ABV}_{\mathrm{e}}$ equation has been corrected according to a recently published erratum [27]:

$$
\mathrm{ABV}_{\mathrm{e}}=\frac{\mathrm{ABV}_{\mathrm{b}} \times \text { Final RBV }}{100},
$$

where Final RBV is RBV measured in the last $15 \mathrm{~min}$.

Once we determine Initial $\mathrm{ABV}$ and Final $\mathrm{ABV}, V_{\text {ref }}$ can be estimated as

$$
V_{\text {ref }}=V_{\text {uf }}+\text { Final ABV - Initial ABV. }
$$

Vascular refilling fraction $\left(F_{\text {ref }}\right)$ is calculated as the ratio of $V_{\text {ref }}$ to prescribed UF volume:

$$
F_{\text {ref }}(\%)=\frac{V_{\text {ref }}}{V_{\text {uf }}} .
$$

\section{IDH Definition}

There is yet no evidence-based consensus in the definition of IDH: while some definitions are based exclusively on systolic blood pressure (SBP) or mean arterial pressure reduction, others require associated symptoms or dialysis staff intervention [28-33]. In order to be able to compare more easily, we agreed to use IDH definition proposed by Kron et al. [24, 25], also applied in previous studies from our group: an SBP decrease above $20 \mathrm{~mm} \mathrm{Hg}$ during $\mathrm{HD}$ (calculated as the difference between predialysis and lowest blood pressure) accompanied or not by symptoms [34, 35].

\section{Statistical Analysis}

Results are expressed as mean \pm standard deviation, median, or percentage, as appropriate. Each patient serves as his/her own control. Normal distribution of the data was determined using the Shapiro-Wilk test. The paired $t$ test was performed to compare matched data. All analyses were carried out using SPSS Version 20.0. The significance was set at $p<0.05$.

Beta-Blockers and Vascular Refilling in Hemodialysis Patients

\section{Results}

\section{Patient Characteristics}

A total of 20 individuals receiving maintenance HD were included in the study. Overall, study patients had a mean age of $74.9 \pm 8.0$ years, 16 were men, and the most common end-stage renal disease (ESRD) cause was diabetic nephropathy $(n=9)$, followed by nephrosclerosis $(n=5)$. Mean HD vintage was $26.6 \pm 24.5$ months. CV disease was frequent among the cohort: 14 patients had atrial fibrillation, 12 had ischemic cardiopathy, and 17 patients had cerebrovascular disease. According to inclusion criteria, all patients had previous $\beta$-blocker prescription: 2 patients were receiving atenolol, 4 patients metoprolol, 4 bisoprolol, and 10 patients had carvedilol prescription. Other antihypertensive drugs prescribed were calcium channel blockers $(n=14)$, a-blockers $(n=10)$, and angiotensin-converting enzyme inhibitors or angiotensin receptor blockers $(n=5)$.

Mean HD duration was $219.00 \pm 14.92 \mathrm{~min}$, with a mean UF rate of $836.98 \pm 275.52 \mathrm{~mL} / \mathrm{h}$ and a specific UF rate of $12.67 \pm 4.53 \mathrm{~mL} / \mathrm{kg} / \mathrm{h}$. Sixteen patients had a functioning arteriovenous fistula while the remaining 4 had a central venous catheter. Mean blood flow was $350 \pm 39.74$ $\mathrm{mL} / \mathrm{min}$.

\section{Primary Analysis}

Predialysis and postdialysis hemodynamic data are shown in Table 2. An overall analysis of the data did not show statistical differences between the 2 profiles (non$\beta \mathrm{b}$ profile and $\beta \mathrm{b}$ profile) when comparing mean specific $\mathrm{ABV}_{\mathrm{b}}(92.89 \pm 24.26 \mathrm{~mL} / \mathrm{kg}$ and $90.17 \pm 15.34 \mathrm{~mL} / \mathrm{kg}$, respectively, $p=0.585)$ or mean specific $\mathrm{ABV}_{\mathrm{e}}(79.30 \pm$ $23.52 \mathrm{~mL} / \mathrm{kg}$ and $75.14 \pm 14.12 \mathrm{~mL} / \mathrm{kg}$, respectively, $p=$ 0.376). UF was also similar in both conditions, with a mean value of $3.089 \pm 1.071 \mathrm{~mL}$ for the non- $\beta \mathrm{b}$ profile and $2.972 \pm 1.147 \mathrm{~mL}$ for the $\beta \mathrm{b}$ profile $(p=0.365)$. Although the $\beta \mathrm{b}$ profile showed lower $\mathrm{V}_{\mathrm{REF}}$ and higher $\mathrm{ABV}$ drop, these differences did not reach statistical significance. However, a significantly higher $\mathrm{F}_{\mathrm{REF}}$ in the non- $\beta \mathrm{b}$ profile was observed $(70.01 \pm 6.80 \%$ vs. $63.14 \pm 11.65 \%$; $p=$ $0.015)$.

\section{IDH Incidence}

Predialysis SBP was similar in both profiles (143.5 \pm $23.7 \mathrm{~mm} \mathrm{Hg}$ in the non- $\beta \mathrm{b}$ profile and $144.4 \pm 21.2 \mathrm{~mm}$ $\mathrm{Hg}$ in the $\beta \mathrm{b}$ profile). However, IDH was significantly more frequent when patients were under $\beta$-blocker treatment: $60 \%$ patients $(33.3 \%$ were receiving bisopro- 
Table 2. Predialysis and postdialysis volume data comparing non- $\beta$ b profile and $\beta b$ profile

\begin{tabular}{llll}
\hline & Non- $\beta$ b profile & $\beta$ b profile & $\begin{array}{l}\text { Paired } t \text { test } \\
p \text { value }\end{array}$ \\
\hline UF volume, $\mathrm{mL}$ & & & 0.365 \\
Initial absolute blood volume, L & $3.080 \pm 1.071$ & $2.972 \pm 1.147$ & 0.590 \\
Initial specific absolute blood volume, $\mathrm{mL} / \mathrm{kg}$ & $6,17 \pm 1.39$ & $6.00 \pm 0.96$ & 0.585 \\
Final absolute blood volume, L & $92.89 \pm 24.26$ & $90.17 \pm 15.34$ & 0.332 \\
Final specific absolute blood volume, $\mathrm{mL} / \mathrm{kg}$ & $5.27 \pm 1.39$ & $4.99 \pm 0.89$ & 0.357 \\
Absolute blood volume drop, L & $79.30 \pm 23.52$ & $75.98 \pm 14.09$ & 0.079 \\
Vascular refilling volume, L & $0.90 \pm 0.30$ & $1.01 \pm 0.33$ & 0.061 \\
Refilling fraction, \% & $2.18 \pm 0.85$ & $1.96 \pm 0.99$ & 0.015 \\
\hline
\end{tabular}

Table 3. Predialysis and postdialysis volume data for the carvedilol group

\begin{tabular}{llll}
\hline & Noncarvedilol profile & Carvedilol profile & $\begin{array}{c}\text { Paired } t \text { test } \\
p \text { value }\end{array}$ \\
\hline UF volume, $\mathrm{mL}$ & & $2.820 \pm 1.111$ & 0.083 \\
Initial absolute blood volume, L & $3.005 \pm 1.263$ & $5.72 \pm 0.76$ & 0.812 \\
Initial specific absolute blood volume, $\mathrm{mL} / \mathrm{kg}$ & $5.79 \pm 0.78$ & $86.50 \pm 12.23$ & 0.774 \\
Final absolute blood volume, L & $4.92 \pm 0.91$ & $4.69 \pm 0.71$ & 0.473 \\
Final specific absolute blood volume, $\mathrm{mL} / \mathrm{kg}$ & $74.66 \pm 15.09$ & $71.03 \pm 11.48$ & 0.495 \\
Absolute blood volume, drop L & $0.88 \pm 0.37$ & $1.03 \pm 0.42$ & 0.193 \\
Vascular refilling volume, L & $2.13 \pm 0.92$ & $1.69 \pm 0.87$ & 0.014 \\
Refilling fraction, \% & $70.14 \pm 6.55$ & $59.54 \pm 12.72$ & 0.043 \\
Refilling rate, $\mathrm{mL} / \mathrm{h}$ & $593 \pm 263$ & $478 \pm 253$ & 0.014 \\
\hline
\end{tabular}

lol, $50 \%$ carvedilol, and $16.7 \%$ metoprolol) in the $\beta \mathrm{b}$ profile versus $25 \%$ patients $(25 \%$ were being treated with bisoprolol, $50 \%$ with carvedilol, and $25 \%$ metoprolol) in the non- $\beta$ b profile (risk ratio 2.40 ; $95 \%$ CI: $1.04-$ 5.55).

\section{Effect of Carvedilol on Vascular Refilling}

Ten of the 20 patients included in the study had a carvedilol prescription, with a median dose of $12.5 \mathrm{mg}$ per day (6.25-50). Carvedilol impact on hemodynamics analysis showed that when patients were not under its effect (noncarvedilol profile), they presented a significantly higher $V_{\text {ref }}$ than when they had been previously exposed to the drug (carvedilol profile) $(2.13 \pm 0.92 \mathrm{~L}$ vs. $1.69 \pm$ $0.87 \mathrm{~L}$, respectively; $p=0.014$ ). Similar results were found for $F_{\text {ref }}(70.14 \pm 6.55 \%$ vs. $59.54 \pm 12.72 \%$, respectively; $p=0.043)$ and refilling rate $(593 \pm 263 \mathrm{~mL} / \mathrm{h}$ vs. $478 \pm 278$ $\mathrm{mL} / \mathrm{h} ; p=0.014)$. Data are shown in Table 3 .

\section{Discussion}

This study evaluated the effect of $\beta$-blockers on intradialytic hemodynamics among individuals receiving maintenance HD. To date, there are no previous studies comparing the effect of $\beta$-blockers on $V_{\text {ref }}$ and $F_{\text {ref }}$ in the dialysis population, as its measurement has not been easily available in clinical practice. Since Kron et al. [24] published their new methodology to asses vascular refilling during HD treatments, several authors have been using it to provide an in-depth understanding of hemodynamics during HD [3438]. A first observational study conducted by our group, including a cohort of 31 dialysis patients, showed lower $F_{\text {ref }}$ in patients under previous $\beta$-blocker treatment (mean $F_{\text {ref }}$ of $67.82 \%$ in patients under $\beta$-blockers vs. $80.59 \%$ in patients without these drugs; $p=0.007$ ) [26]. In an attempt to avoid biases, as patients receiving $\beta$-blockers might have $\mathrm{CV}$ comorbidities that affect their $F_{\text {ref, we performed this }}$ crossover study to deeply investigate the relationship between $\beta$-blockers and vascular refilling. 
The results show that $\beta$-blocker use among dialysis patients led to a higher risk of IDH if administered before the HD session, when compared to performing the same HD treatment without the effect of the drug (risk ratio 2.40; 95\% CI: $1.04-5.55)$. This may be related to the fact that $\beta$-blockers impair intradialytic physiologic compensatory responses to ABV drop caused by UF, such as reduction of cardiac output and reduction of pre- and postsynaptic vasoconstrictor nerve activity, with a secondary increase in hydrostatic pressure in the capillary bed that may inhibit refilling [39]. A primary analysis showed a slightly lower $V_{\text {ref }}$ in the $\beta \mathrm{b}$ profile when compared to non- $\beta$ b profile, with a nonsignificant greater $A B V$ drop. Moreover, data showed a significantly lower $F_{\text {ref }}$ in the $\beta \mathrm{b}$ profile when compared to the non- $\beta$ b profile (63.14 \pm 11.65 vs. $70.01 \pm 6.80 \%$; $p=0.015)$. These data corroborate the findings of the previously mentioned study conducted by our group [26].

We studied separately patients under carvedilol treatment, as out of the $\beta$-blockers included in the study, it is the only noncardioselective and low dialyzable, which might enhance its systemic effect. There are scanty data about the effect of carvedilol on intradialytic hemodynamics in HD patients. In the Beta-Blocker to Lower Cardiovascular Dialysis Events (BLOCADE) trial, Roberts et al. [14] attempted to advance our knowledge on carvedilol effects on HD patients compared to placebo; nevertheless, they could not recruit planned sample size: among 1,443 patients screened, only 354 met eligibility, and just 91 provided consent and finally 72 entered the 6 -week run-in period. Of these, only 49 participants tolerated carvedilol therapy and progressed to randomization [14]. Cice et al. [12] also performed an RCT, mentioned elsewhere, comparing carvedilol to placebo in HD patients, showing left ventricular function and clinical status improvement. Despite its proven long-term CV benefits, no study to date has analyzed carvedilol's immediate effect on $V_{\text {ref }}$ and $F_{\text {ref. }}$ In this study, we found evidence that being dialyzed under carvedilol effect associated a significant impairment in $V_{\text {ref, }}, F_{\text {ref, }}$ and refilling rate when compared to noncarvedilol profile. Some authors recommend that highly dialyzable $\beta$-blockers such as atenolol should be administered after HD in order to achieve longer effect, as lowering its plasma concentration during the dialysis treatment may affect patient's survival outcome $[40,41]$. Since carvedilol seems to impair vascular refilling, it could also be beneficial to take this drug postdialysis in order to improve patients' hemodynamics and technique tolerance. However, larger studies are needed.

Beta-Blockers and Vascular Refilling in Hemodialysis Patients

\section{Conclusion}

Administering $\beta$-blockers before $\mathrm{HD}$ associated a higher risk of IDH due to a greater decrease in $F_{\text {ref. }}$ Out of $\beta$-blockers, patients dialyzed under carvedilol effect showed a lower $V_{\text {ref }}$ and $F_{\text {ref, }}$, probably related to its noncardioselectivity and lower dializability. Patients might benefit from having carvedilol administered after HD.

\section{Statement of Ethics}

All procedures performed in studies involving human participants were in accordance with the ethical standards of the institutional review board at which the studies were conducted (IRB Approval No. 212/19) and with the 1964 Helsinki Declaration and its later amendments or comparable ethical standards. The study protocol was approved by the institute's committee on human research. Informed consent was obtained from the patients to publish.

\section{Conflict of Interest Statement}

The authors have no conflicts of interest to declare.

\section{Funding Sources}

No funding was required.

\section{Author Contributions}

Álvarez Nadal, Marta, contributed to conception and design of the work; acquisition and analysis of data; interpretation of data; drafting the work; revising the work critically; final approval. Viera Ramírez, Elizabeth Romelia, contributed to acquisition and analysis of data; drafting the work. García Vallejo, María, contributed to acquisition and analysis of data; drafting the work. Martín Capón, Irene, contributed to interpretation of data; drafting the work. Fernández Lucas, Milagros, contributed to conception and design of the work; interpretation of data; revising the work critically; final approval.

\section{Data Availability Statement}

All data generated or analyzed during this study are included in this article. Further enquiries can be directed to the corresponding author. 


\section{References}

1 Wanner C, Amann K, Shoji T. The heart and vascular system in dialysis. Lancet. $2016 \mathrm{Jul}$; 388(10041):276-84.

2 Frankenfield DL, Weinhandl ED, Powers CA, Howell BL, Herzog CA, St Peter WL. Utilization and costs of cardiovascular disease medications in dialysis patients in medicare part D. Am J Kidney Dis. 2012 May;59(5):670-81.

3 K/DOQI Workgroup. K/DOQI clinical practice guidelines for cardiovascular disease in dialysis patients. Am J Kidney Dis. 2005 Apr; 45(4 Suppl 3):S1-153.

4 Coca SG, Krumholz HM, Garg AX, Parikh CR. Underrepresentation of renal disease in randomized controlled trials of cardiovascular disease. JAMA. 2006 Sep 20;296(11):1377-84.

5 Konstantinidis I, Nadkarni GN, Yacoub R, Saha A, Simoes P, Parikh CR, et al. Representation of patients with kidney disease in trials of cardiovascular interventions: an updated systematic review. JAMA Intern Med. 2016 Jan 1;176(1):121-4.

6 Wu P-H, Lin Y-T, Liu J-S, Tsai Y-C, Kuo M-C, Chiu Y-W, et al. Comparative effectiveness of bisoprolol and carvedilol among patients receiving maintenance hemodialysis Clin Kidney J. 2021 Jan 4;14:983-90.

7 López-Sendón J, Swedberg K, McMurray J, Tamargo J, Maggioni AP, Dargie H, et al. Expert consensus document on beta-adrenergic receptor blockers. Eur Heart J. 2004 Aug; 25(15):1341-62.

8 Bristow MR. Pathophysiologic and pharmacologic rationales for clinical management of chronic heart failure with beta-blocking agents. Am J Cardiol. 1993 Mar 25;71(9): $12 \mathrm{C}-22$.

9 Bouzamondo A, Hulot JS, Sanchez P, Cucherat M, Lechat P. Beta-blocker treatment in heart failure. Fundam Clin Pharmacol. 2001 Apr;15(2):95-109.

10 Jin J, Guo X, Yu Q. Effects of beta-blockers on cardiovascular events and mortality in dialysis patients: a systematic review and metaanalysis. Blood Purif. 2019;48(1):51-9.

11 Cice G, Ferrara L, Di Benedetto A, Russo PE, Marinelli G, Pavese F, et al. Dilated cardiomyopathy in dialysis patients - beneficial effects of carvedilol: a double-blind, placebo-controlled trial. J Am Coll Cardiol. 2001 Feb; 37(2):407-11.

12 Cice G, Ferrara L, D’Andrea A, D’Isa S, Di Benedetto A, Cittadini A, et al. Carvedilol increases two-year survival in dialysis patients with dilated cardiomyopathy: a prospective, placebo-controlled trial. J Am Coll Cardiol. 2003 May 7;41(9):1438-44.

13 Agarwal R, Sinha AD, Pappas MK, Abraham TN, Tegegne GG. Hypertension in hemodialysis patients treated with atenolol or lisinopril: a randomized controlled trial. Nephrol Dial Transplant. 2014 Mar;29(3): 672-81.
14 Roberts MA, Pilmore HL, Ierino FL, Badve SV, Cass A, Garg AX, et al. The $\beta$-blocker to lower cardiovascular dialysis events (BLOCADE) feasibility study: a randomized controlled trial. Am J Kidney Dis. 2016 Jun;67(6): 902-11.

15 Wu P-H, Lin Y-T, Kuo M-C, Liu J-S, Tsai Y-C, Chiu Y-W, et al. $\beta$-blocker dialyzability and the risk of mortality and cardiovascular events in patients undergoing hemodialysis. Nephrol Dial Transplant. 2020 Nov 1;35(11): 1959-65.

16 Chen J, Gul A, Sarnak MJ. Management of intradialytic hypertension: the ongoing challenge. Semin Dial. 2006 Apr;19(2):141-5.

17 Chazot C, Jean G. Intradialytic hypertension: it is time to Act. Nephron Clin Pract. 2010; 115(3):c182-8.

18 Redon J, Martinez F, Cheung AK. Special considerations for antihypertensive agents in dialysis patients. Blood Purif. 2010;29(2):93-8.

19 Tieu A, Velenosi TJ, Kucey AS, Weir MA, Urquhart BL. $\beta$-Blocker dialyzability in maintenance hemodialysis patients: a randomized clinical trial. Clin J Am Soc Nephrol. 2018 Apr 6;13(4):604-11.

20 Levin NW, Kotanko P, Eckardt K-U, Kasiske BL, Chazot C, Cheung AK, et al. Blood pressure in chronic kidney disease stage $5 \mathrm{D}$ - report from a kidney Disease: improving global outcomes controversies conference. Kidney Int. 2010 Feb;77(4):273-84.

21 Daugirdas JT. Pathophysiology of dialysis hypotension: an update. Am J Kidney Dis. 2001 Oct;38(4):S11-7.

22 Daugirdas JT. Dialysis hypotension: a hemodynamic analysis. Kidney Int. $1991 \mathrm{Feb} ; 39(2)$ : 233-46.

23 Schneditz D, Roob J, Oswald M, Pogglitsch H, Moser M, Kenner T, et al. Nature and rate of vascular refilling during hemodialysis and ultrafiltration. Kidney Int. 1992 Dec;42(6): 1425-33.

24 Kron J, Schneditz D, Leimbach T, Aign S, Kron S. A simple and feasible method to determine absolute blood volume in hemodialysis patients in clinical practice. Blood Purif. 2014;38(3-4):180-7.

25 Kron S, Schneditz D, Czerny J, Leimbach T, Budde K, Kron J. Adjustment of target weight based on absolute blood volume reduces the frequency of intradialytic morbid events: dry weight and absolute blood volume. Hemodial Int. 2018 Apr;22(2):254-60

26 Álvarez Nadal M, Viera Ramírez ER, Martín Capón I, Fernández Lucas M. Absolute blood volume variations and vascular refilling in hemodialysis patients. Semin Dial. 2021 May; 34(3):229-34

27 Erratum. Blood purification. Blood Purif. 2021;50(3):408.

28 Cedeño S, Vega A, Macías N, Sánchez L, Abad S, López-Gómez JM, et al. Intradialytic hypo- tension definitions with mortality prediction capacity in a cohort of haemodialysis patients. Nefrologia. 2020 Aug;40(4):403-13.

29 Ashby D, Borman N, Burton J, Corbett R, Davenport A, Farrington K, et al. Renal association clinical practice guideline on haemodialysis. BMC Nephrol. 2019 17;20(1):379.

30 Kooman J, Basci A, Pizzarelli F, Canaud B, Haage P, Fouque D, et al. EBPG guideline on haemodynamic instability. Nephrol Dial Transplant. 2007 May;22(Suppl 2):ii22-44.

31 Hirakata H, Nitta K, Inaba M, Shoji T, Fujii H, Kobayashi S, et al. Japanese Society for Dialysis Therapy guidelines for management of cardiovascular diseases in patients on chronic hemodialysis. Ther Apher Dial. 2012 Oct; 16(5):387-435

32 Chou JA, Streja E, Nguyen DV, Rhee CM, Obi $\mathrm{Y}$, Inrig JK, et al. Intradialytic hypotension, blood pressure changes and mortality risk in incident hemodialysis patients. Nephrol Dial Transplant. 2018 01;33(1):149-59.

33 Sands JJ, Usvyat LA, Sullivan T, Segal JH, Zabetakis $\mathrm{P}$, Kotanko P, et al. Intradialytic hypotension: frequency, sources of variation and correlation with clinical outcome. Hemodial Int. 2014 Apr;18(2):415-22.

34 Kron S, Schneditz D, Leimbach T, Czerny J, Aign S, Kron J. Determination of the critical absolute blood volume for intradialytic morbid events: Critical absolute blood volume. Hemodial Int. 2016 Apr;20(2):321-6.

35 Álvarez Nadal M, Martín Capón I, Viera Ramírez ER, Fernández Lucas M. Absolute blood volume variations during hemodialysis: does dialysate temperature play a role? Semin Dial. 2021 May;34(3):229-34.

36 Kron S, Schneditz D, Leimbach T, Aign S, Kron J. Vascular refilling is not reduced in dialysis sessions with morbid events. Blood $\mathrm{Pu}$ rif. 2017;43(4):309-14.

37 Mitsides N, Pietribiasi M, Waniewski J, Brenchley P, Mitra S. Transcapillary refilling rate and its determinants during haemodialysis with standard and high ultrafiltration rates. Am J Nephrol. 2019;50(2):133-43.

38 Alayoud A, Belarabi M, Labrini F, Badaoui M, Zajjari Y, Maoujoud O, et al. Utility of a blood volume monitor in the management of anemia in dialysis by computing the total hemoglobin mass. Hemodial Int. 2019 Oct;23(4):419-25.

39 Heintzen MP, Strauer BE. Peripheral vascular effects of beta-blockers. Eur Heart J. 1994 Aug;15(Suppl C):2-7.

40 Sinha AD, Agarwal R. Clinical pharmacology of antihypertensive therapy for the treatment of hypertension in CKD. Clin J Am Soc Nephrol. 2019 May 7;14(5):757-64.

41 Weir MA, Dixon SN, Fleet JL, Roberts MA, Hackam DG, Oliver MJ, et al. $\beta$-Blocker dialyzability and mortality in older patients receiving hemodialysis. J Am Soc Nephrol. 2015 Apr;26(4):987-96. 